\title{
Quinoa Crop as an Ingredient of Functional Foods and Its Utilization in Bread
} Making

\author{
M.H. Abdel-Al ${ }^{1}$, Faten F. Abdel-salam ${ }^{1}$ and Essam E. Shalaby ${ }^{2}$
}

${ }^{1}$ Department of Food Science and Technology, Faculty of Agriculture, El-Shaby, 21545, University of Alexandria, Alexandria, Egypt.

${ }^{2}$ Department of Agronomy, Faculty of Agriculture, El-Shaby 21545, University of Alexandria, Alexandria, Egypt.

$$
\text { Received: } 10 \text { Dec. 2019/ Accepted 10 Mar. } 2020 \text { / Publication date: } 30 \text { Mar. } 2020
$$

\begin{abstract}
Special attention has been given in recent years to quinoa (Chenopodium quinoa Willd.) due to its high nutritional value and high-quality protein content. Quinoa seeds also contain various bioactive substances. Quinoa seed is rich source of phenolic compounds, particularly flavonoids, with healthpromoting and/or disease preventing properties. Quinoa (Chenopodium quinoa Willd.) is a pseudocereal and is a native crop grows in many different regions and under various climate conditions. Quinoa has a broad genetic diversity, which allows it to adapt to various environments. (Jacobsen, 2003). The total phenolic content of quinoa seeds was studied and was $7.79 \mathrm{mg} / \mathrm{g}$ and the flavonoid content in our investigated quinoa variety was $10.21 \mathrm{mg} / \mathrm{g}$. For bread making, seeds were soaked in tap water overnight for de-bittering. The soaking process stopped when there is no foam formed. Preparing of pan bread was done by using the following ingredients $100 \mathrm{~g}$ wheat flour, $1.5 \mathrm{~g}$ instant active dry yeast, $2.0 \mathrm{~g}$ salt, $2.0 \mathrm{~g}$ sugar, $3.0 \mathrm{~g}$ shortening and water. And substitute the wheat flour by ratios up to $20 \%$ Main results reveal that the loaf specific volume decreased with the substitution with quinoa flour. The panelists found the crumb more dense and compact in bread $20 \%$ of quinoa flour compared to the control and also crust colour, crumb colour, and taste attributes. Bread parameters such as loaf specific volume, weight, crust and sensory properties were affected by the incorporation of quinoa, especially at $20 \%$ of addition, whereas the nutritional quality was increased. These new bread products were still accepted by the panelists. Quinoa is gluten-free and easy to digest; quinoa flour can used in wheatbased and gluten-free baking. Quinoa grains are used to make flour, soups, breakfast cereals. In conclusion, whole quinoa flour could be a good replacement for wheat flour in bread formulations, increasing the product's nutritional value in terms of dietary fiber, minerals, proteins and healthy fats, with only a small depreciation in bread quality at $15 \%$ of flour substitution.
\end{abstract}

Keywords: gluten, free bread, halophyte, nutritional quality, saponin, gluten quality

\section{Introduction}

Attention has been recently given to quinoa (Chenopodium quinoa Willd.) due to its high nutritional value and high-quality protein content and in the same time it can be planted under harsh conditions because it tolerate drought and salinity since it considers a halophyte. Quinoa seeds also contain various bioactive substances such as polyphenols, carotenoids, dietary fiber, and oleic acid, all of them are important to human health. Quinoa (Chenopodium quinoa Willd.) is a pseudocereal and is a native plant grows in many different regions and under various climate conditions. Quinoa has a broad genetic diversity, which allows it to adapt to various environments. (Jacobsen, 2003). The history of its human consumption reaches back 5000 years ago. The edible seeds of quinoa are small, round and flat. Due to its significant nutritive value and ability to adapt to a wide range of agro-ecological conditions, quinoa is becoming of increasing interest worldwide. Most developing countries, including Egypt, face serious challenges in the process of achieving national food security at the level of strategic crops, at a time when environmental degradation and depletion of natural resources. The economic study of the cultivation of the quinoa plant could solve the problem of food security in Egypt and reduce food poverty gap (Hossam et al., 2014). Quinoa has been selected by FAO as one of the crops destined to offer food security in the $21^{\text {st }}$ century (Jacobsen, 2003). Quinoa seed contains a balanced set of essential amino acids for humans, making it an unusually complete protein source (Schlick \& Bubenheim, 1993)

Corresponding Author: Essam E. Shalaby, Department of Agronomy, Faculty of Agriculture, El-Shaby 21545, University of Alexandria, Alexandria, Egypt.

E-mail: dr.essamshalaby@gmail.com 
Also, it is a good source of dietary fibre and unsaturated fats (Alvarez-Jubete et al., 2010). In addition, it contains adequate levels of vitamins and minerals (Konishi et al., 2004). But, beyond their basic nutritional function of supplying nutrients, different authors have reported that quinoa seeds represent a potentially rich source of phenolic compounds, particularly flavonoids, with health-promoting and/or disease preventing properties. Phenolic compounds are secondary plant metabolites which can prevent several degenerative diseases dependent on oxidative stress, through antioxidant action and/or the modulation of several protein functions (Hirose et al., 2010). The optimum extraction of phenolic compounds is, therefore, an important step prior to eventual purification and application of the extracts. Considering the diversity of natural sources of polyphenols, as well as the structure and physicochemical properties of these compounds, specific processes should bedesigned and optimized for each phenolic source (Silva et al., 2007). Saponins glycosides widely distributed in the plant kingdom include a diverse group of compounds characterized by their structure containing a steroidal or triterpenoid aglycone and one or more sugar chains. Their structural diversity is reflected in their physicochemical and biological properties. Saponins are responsible for the characteristic astringent or bitter taste associated with quinoa (Tarade et al., 2006). To be edible, the saponin must be removed from the quinoa seeds. Traditionally, saponin has been removed by laboriously hand scrubbing the quinoa with alkaline water. The saponin content is checked by placing the grain in a tube, adding water and vigorously shaking for $30 \mathrm{~s}$. If no foaming occurs, all saponins are assumed to have been removed. Additionally, saponin content can potentially be reduced through either an extrusion or a roasting process. Quinoa can be classified via its saponin content, which is dependent on the quinoa variety: 'sweet' (free from or containing $<0.11 \%$ of free saponins) or 'bitter' (containing $>0.11 \%$ of free saponins) (Kozioł, 1992; Gee et al., 1993; Soliz-Guerrero, 2002; Stuardo and San Martın, 2008; Martınez et al., 2009). Generally, the saponin content in seeds of sweet genotypes varies from 0.2 to $0.4 \mathrm{~g} / \mathrm{kg}$ dry matter and in bitter genotypes from 4.7 to $11.3 \mathrm{~g} / \mathrm{kg}$ dry matter (Mastebroek et al., 2000). Some experts have called for the development of saponin-free strains of quinoa since the saponin removal process has limited the production and marketing of this crop. Ecologists observe, though, that the bitter-tasting saponin probably prevents insect and bird predation so its removal might lead to increased reliance on insecticides. Mixolab has been likely used in many studies for probing dough behaviour during processing conditions. By using Mixolab it is possible to record the mechanical changes due to mixing and heating simulating the mechanical work as well as the heat conditions that might be expected during the bread making and bread baking processes. The advantage of using Mixolab is that in a single test one can measure properties of proteins and starch.

Water absorption (\%) - WA or the percentage of water required for the dough to produce a torque of 1.1; dough development time (min) - DDT or the time to reach the maximum torque at $30{ }^{\circ} \mathrm{C}$; stability (min) or time until the loss of consistency is lower than $11 \%$ of the maximum consistency reached during the mixing,; initial maximum consistency $(\mathrm{C} \max )(\mathrm{Nm})-\mathrm{C} 1$, used to determine the water absorption; torque at the end of the holding time at $30^{\circ} \mathrm{C}(\mathrm{Nm})-\mathrm{C} 1.2$; and mechanical weakening $(\mathrm{Nm})$ - the torque difference between $\mathrm{C} 1$ and $\mathrm{C} 1.2$ were the main five parameters which refer to dough characteristics during mixing at constant temperature, $30^{\circ} \mathrm{C}$, describing the dough behaviour during processing stage.

During mixing hydration of the compounds and the stretching and alignment of the proteins occurs, which lead to the formation of a three-dimensional viscoelastic structure, Kovacs et al., (2004) wheat flour dough, which served as a control sample was characterized with low DDT, long stability and great resistance to the mechanical constraint. These properties of wheat flour are related to its unique protein composition and quality. Namely, as it is already known, wheat proteins mainly consist of gluten proteins (approximately about $80-85 \%$ of total wheat protein) which comprise of prolamins (in wheat - gliadins) and glutelins (in wheat - glutenins). In contrast, non-gluten proteins (albumins and globulins) are presented in $15-20 \%$ of the total wheat proteins. Wheat storage protein (gluten) is a viscoelastic protein responsible for dough structure formation A gluten index test was recently introduced as a quicker method to measure wheat processing quality in comparison with the classical instrumental methods, such as a mixograph and farinograph. It is also a criterion defining whether the gluten quality is weak, normal, or strong. The gluten index test has gained wide acceptance as a method of determining gluten strength and is used in international trade specifications.

Damage starch is a starch granule that is broken up into pieces. Not only does it increase water absorption and affect dough rheology, but it also increases food supply to the yeast and is more 
susceptible to fungal alpha-amylase. Starch represents $67-68 \%$ of whole grain wheat and between 78 $82 \%$ of the flour produced from milling. The semi-crystalline structure of the starch granule in the grain kernel can be damaged by mechanical operations, particularly the milling process.

Gluten-free bread (GI) is a criterion defining whether the gluten quality is weak (GI $<30 \%$ ), normal (GI $=30-80 \%$ ), or strong ( $\mathrm{GI}>80 \%$ ) Cubadda et al., (1992). Wheat with similar protein contents can be classified according to GI values.

Gluten forming proteins play key roles in the baking quality of wheat by improving the water absorption capacity, extensibility and elasticity of the dough. The quantity and quality of gluten are considered the most important quality parameters of wheat flour. Wet gluten content is determined by washing the dough obtained from flour or wheat meal, with water or other solution in certain conditions, to remove the starch and other soluble compounds of the sample (Mis, 2000).

Quinoa is gluten-free and it is considered easy to digest; quinoa flour can be used in wheat-based and gluten-free baking. Quinoa grains are used to make flour, soups, breakfast cereals.

\section{Materials and Methods}

Materials:

Quinoa seeds: Five $\mathrm{Kg}$ of quinoa seeds variety Regalona

Chemicals: Folin-Ciocalteu's phenol reagent, tannic acid, 1-diphenyl-2-picrylhydrazyl radical (DPPH) and rutin from Sigma-Aldrich Company (St. Louis, Missouri, USA), all GC chemicals from Fisher Scientific Inc. caffeine standard from ADH company was used. All solvents and chemicals used for analysis were of analytical grade.

Ingredients Bread-making ingredients such as (wheat flour extracting rate $72 \%$, instant yeast, and salt, etc), and oil were purchased from the local market at Alexandria, Egypt.

\section{Methods:}

\section{Technological methods:}

\section{Preparation and de-bittering:}

Quinoa seeds were soaked in tap water overnight (for 10 hours) for de-bittering. The soaking process stopped when there is no foam formed.

\section{Preparing of pan bread:}

The ingredients were: $100 \mathrm{~g}$ wheat flour, $1.5 \mathrm{~g}$ instant active dry yeast, $2.0 \mathrm{~g}$ salt, $2.0 \mathrm{~g}$ sugar, 3.0 $\mathrm{g}$ shortening and water. All ingredients were placed in a mixing bowl at $28 \pm 2.0{ }^{\circ} \mathrm{C}$ and mixed for 6 min, after mixing, the formulated dough was rounded manually by folding for 20 times, then the bulk dough was left to rest for $10 \mathrm{~min}$. The prepared dough $(120 \mathrm{~g})$ was placed in lightly greased a baking pan. The dough was proved for $80 \mathrm{~min}$ in a cabinet at $30 \pm 0.5$ C and $85 \%$ relative humidity then baked for $20 \mathrm{~min}$ at $250{ }^{\circ} \mathrm{C}$ in an electric oven. After the baked, bread was cooled for 60 min at room temperature $\left(25 \pm 2.0^{\circ} \mathrm{C}\right)$ and then packed in polyethene bags and stored for 6 days at room temperature $\left(25 \pm 2.0^{\circ} \mathrm{C}\right)$ (El-Porai et al., 2013).

\section{Physical methods:}

Rheological properties were determined by Mixolab (Duisburg, Germany). Damage starch was determined as reported by Debit, 2007. The loaf volume was measured by rapeseed displacement method according to AACC2000. Specific volume was calculated from loaf volume and loaf weight just after one hour of baking. , By dividing the sample volume (cm3) by the sample weight $(\mathrm{g})$. Specific volume is expressed in cubic centimetres per gram $\left(\mathrm{cm}^{3} / \mathrm{g}\right)$.

\section{Chemical methods:}

Moisture, crude protein, crude fat, crude fiber and carbohydrate (by difference) of quinoa seeds powder and pan bread formulas were done according to the standard A.O.A.C. methods 2000. Saponins were determined according to Harbome (1973). Alkaloids were determined as reported by John et al., (2014), and caffeine was used as a standard. 
Total phenolic (TP) content of quinoa flour was assayed by Folin -Ciocalteu reagent and tannic acid as a standard (Singleton et al., 1965). The reaction mixture was kept in dark at ambient temperature $\left(22 \pm 2{ }^{\circ} \mathrm{C}\right.$ ) for $2 \mathrm{hrs}$ before measuring the absorbance at a wavelength of $765 \mathrm{~nm}$ using UV-Vis. Spectrophotometer ( Laxco-Alpha-1102, Suite) (Ozgen et al., 2008).

Total flavonoids content of quinoa flour were determined spectrophotometrically at a wavelength of $430 \mathrm{~nm}$ using UV-Vis Spectrophotometer (Laxco-Alpha-1102, Suite) as mentioned .The method is based on the formation of a complex of flavonoid- aluminium. Rutin was used as a standard and the flavonoid level was expressed as $\mathrm{mg}$ of rutin equivalent per one $\mathrm{kg}$ of sample.

The DPPH (2, 2-diphenyl-1-picrylhydrazyl) radical scavenging activity of methanolic extracts was determined following the method reported by Jayanthi and Lalitha (2011) and compared by standard ascorbic acid.

FRAP measures the total antioxidant capacity using potassium ferricyanide $\left(\mathrm{Fe}^{+++}\right)$to form potassium ferrocyanide $\left(\mathrm{Fe}^{++}\right)$, which reacts with ferric chloride to form a ferric ferrous complex with an absorption maximum at a wavelength of $700 \mathrm{~nm}$. using UV-Vis spectrophotometer ( Laxco-Alpha1102 , Suite). Blank was prepared without using the sample. A calibration curve was prepared using an aqueous solution of potassium ferrocyanide as a standard. The increase of absorbance of the reaction mixture indicates an increase in reducing power. The percentage of reducing power was calculated by the following equation:

$\%$ increasing in the reducing power $=($ A test $/ \mathrm{B}$ blank $)-1$ X 100

Whereas $\mathrm{A}$-the absorbance of the tested solution and $\mathrm{B}$ - the absorbance of the blank.

\section{Sensory Evaluation}

Crust and crumb colour, taste, odour, cell distribution and acceptability of pan bread were evaluated by randomly chosen ten panellists of the members of the Food Science and Technology Department, Faculty of Agriculture, Alexandria University, Egypt. A ten point scale was used, whereas; 9 means the best and 1 means the least, as described by Piggott (1988).

\section{Statistical Analysis}

The obtained data from this study were analyzed using software version 917 (stats soft, Inc. USA, 2003). Analysis of variance (ANOVA) was performed to determine the differences among samples. Differences among samples were considered significant at $\mathrm{p}<0.05$ using Duncans's multiple difference test (Steel et al., 1980).

\section{Results and Discussion}

Data in Table (1) shows some physical properties of the studied quinoa seeds. The determination of the physical properties of quinoa seeds like those of other seeds is useful for improving the technology associated with the different operations and equipment related to the postharvest process such as cleaning, classification, transport, aeration, drying and storage.

The average length of the seeds was $2.17 \mathrm{~mm}$, the width of the seeds was $2.09 \mathrm{~mm}$. the length and the width, are approximately equal due to the round longitudinal section. One of the major standards of seed quality is the weight of 1000 seeds. The weight of 1000 seeds was $6.30 \mathrm{~g}$.

Table 1: Some physical properties and the dimensions of quinoa seeds.

\begin{tabular}{ll}
\hline Property & Value \pm SD \\
\hline Length $(\mathbf{m m})$ & $2.17 \pm 0.33$ \\
Width $(\mathbf{m m})$ & $2.09 \pm 0.27$ \\
The weight of 1000 seed $(\mathbf{g})$ & $6.30 \pm 0.23$ \\
\hline
\end{tabular}

Results in Table (2) show a summary of the proximate compositions of quinoa flour. The nutrient contents of quinoa varied considerably, where the highest value was protein $(14.49 \%)$ and the lowest value was crude fiber $(3.50 \%)$. The highest protein content of quinoa (variety unknown) was $15.7 \%$ in Italy (Nowak et al., 2016) The differences are possibly due to the interactions of several factors, such as varieties, cultivars, analytical methods and environmental conditions. 
Table 2: The proximate chemical composition and fibers content of quinoa flour.

\begin{tabular}{ll}
\hline Component & Value \pm SD \\
\hline Moisture (\%) & $11.60 \pm 0.37$ \\
Protein (\%) & $14.49 \pm 0.14$ \\
Ash (\%) & $4.64 \pm 0.26$ \\
Fats (\%) & $8.67 \pm 0.49$ \\
NDF (\%) & 14.09 \\
ADF (\%) & 5.60 \\
Crude fibers (\%) & 3.50 \\
NFE (\%) * & 49.01 \\
\hline
\end{tabular}

*Nitrogen Free Extract (NFE) $=100-\{$ Protein + Ash+ Fat+ Fibers $\}$

Table 3 shows the content of saponin in quinoa flour before and after soaking for 10 hours. Saponins are a wide group of glycosides found in plants, they are water soluble and form foaming solutions. Saponins are steroid or triterpenoid glycosides, with the latter found more commonly in crops (Francis et al., 2002). These compounds have a bitter taste and are considered toxic in large amounts. They are present in the whole quinoa plant, where their natural function is to defend the plant from the external medium. In general, quinoa seeds contain saponins in the seed coat (except sweet varieties, without saponin or containing less than $0.11 \%$ ). Saponins are the main antinutritional factor present in the seed cover (Ruales and Nair, 1992, 1993). According to their chemical structure, saponins can be partially removed by washing with water (Chauhan et al., 1999), but even after washing some saponin remains in the seed. Zhu et al. (2002) recommended the use of slightly alkaline water rather than neutral water to de-bitter quinoa seeds. Brady et al. (2007) have reported that the bitter taste imparted by saponins could potentially be reduced by extrusion and roasting processes. Saponins are compounds that contain sugar chains and a triterpenoid aglycone (sapogenin) in their structure (Sparg et al., 2004).

Table 3: Some anti-nutritional factors of quinoa flour

\begin{tabular}{ll}
\hline Component & Value \\
\hline 1-Saponin (\%) & $0.36 \pm 0.01$ \\
a- In the raw flour & $0.24 \pm 0.041$ \\
b- In the flour of the soaked seeds in water for 10 hours & $0.211 \pm 0.019$ \\
2- Alkaloids as (mg Caffeine equivalent/ 100g sample) & \\
\hline
\end{tabular}

Zhu et al. (2001) have isolated six flavonol glycosides from QS; these compounds exhibited antioxidant capacity, suggesting that quinoa can serve as a good source of free radical scavenging agents.

The total phenolic content of quinoa variety studied in this investigation was $7.79 \mathrm{mg} / \mathrm{g}$ as shown in Table 4. Nsimba et al., (2008) studied the phenolic content of five different varieties of quinoa grown in Japan. They found a wide range of total phenolics content was found in studied plant materials. Their content ranged from $94.3 \pm 3.0$ to $148 \pm 1.9 \mathrm{mg} / \mathrm{g}$ tannic acid equivalent (TAE) of dried samples, with an average of $121 \mathrm{mg} / \mathrm{g}$ TAE. Among the five plant materials in their study. The difference in the concentration of the phenolic between the different quinoa varieties might be explained by the difference in the environmental conditions or genetic background. Plant phenolics are biosynthesized following different routes; the shikimic acid pathway is the most biosynthetic route involved. The antioxidant activity assessed allowed to establish their antioxidant capacity of this product and the good correlations with total phenolic and flavonoid contents. The results of this study suggested that quinoa flours are a valid source of natural compounds with significant antioxidant activity and biological properties.

The flavonoid content in our investigated quinoa variety was $10.21 \mathrm{mg} / \mathrm{g}$. Chacaliaza-Rodríguez et al. (2016) found a total flavonoid content of 8.69 and $9.14 \mathrm{mg} \mathrm{RE} / \mathrm{g}$ for quinoas of two varieties in Peru. The differences observed between these values for both TPC and TFC could be explained, at least in part, by the use of different solvents and extraction methods employed. In addition, it is important to mention that the number of polyphenolic compounds, i.e. phenolic acids and flavonoids, are strongly influenced by the genotype (variety and cultivar), soil, environmental conditions, plant maturity, harvest and post-harvest conditions, among others (Skrovankova et al., 2015). 
Table 4: Bioactive components; total phenolics, flavonoids and antioxidant activity of quinoa flour.

\begin{tabular}{ll}
\hline Components & \multicolumn{1}{c}{ Value } \\
\hline Total phenolic content (mg as tannic acid equivalent) & $7.79 \pm 0.47 \mathrm{mg} / \mathrm{g}$ \\
Flavanoids content (mg as rutin equivalent) & $10.21 \pm 0.97 \mathrm{mg} / \mathrm{g}$ \\
Antioxidant activity: & \\
DPPH radical scavenging as mg ascorbic acid/ $\mathbf{1} \mathbf{k g}$ sample & $14.40 \mathrm{ppm}$ ascorbic acid \\
PFRAP as m mole Fe $++/ \mathbf{k g}$ sample & $5.20 \mathrm{mmole} / \mathrm{Kg}$ \\
\hline
\end{tabular}

Solubility is related to the hydrophilic-hydrophobic balance of the proteins and the thermodynamics of its interaction with the solvent. Table 5 shows the water and oil holding capacities of the quinoa flour and the values were 1.5 and $1.09 \mathrm{~g} \mathrm{~g} / \mathrm{g}$ sample, respectively. These parameters are widely related to flour deterioration caused by microorganism, enzymes or non-enzymatic reactions.

Table 5: Some physical properties of quinoa flour.

\begin{tabular}{ll}
\hline Property & Value ( g/g flour) \\
\hline Water absorption (WHC) & $1.5 \pm 0.02$ \\
Oil absorption (OHC) & $1.09 \pm 0.04$ \\
\hline
\end{tabular}

Rheological properties are important in determining the behaviour of wheat flour dough during mechanical handling in addition to their influence on the quality of the finished product. The physical properties of dough of great concern in bread making process. Mixolab analysis revealed a role in studying the dough consistency and rheological properties. The rheological properties of wheat flour as affected by the addition of different ratios of quinoa flour are shown in Table 6 .

Dough development time DDT increased by increasing the addition ratio of quinoa flour to wheat flour. higher DDT, indicating that quinoa flour needs longer time to hydrate all the compounds than wheat flour.

Water absorption of the dough containing $15 \%$ of quinoa flour was $60.2 \%$, while its stability time was (32 min). The higher the max values indicated weaker gluten properties. Quinoa flour is glutenfree but its high content of protein may improve the rheological properties of dough. However, the substitution of wheat flour with flours from other raw materials will alter the rheological properties of dough, as well as the quality of the baked product. It is well known that proteins encountered in nonwheat flours lack the ability to form the gluten network responsible for holding the gas produced during the fermentation. Among different rheological techniques,

Table 6: The effect of quinoa flour on the rheological properties of wheat flour measured by Mixolab.

\begin{tabular}{lcccc}
\hline & \multicolumn{4}{c}{ The ratio of quinoa flour add to wheat flour } \\
Property & Control & $\mathbf{1 0 \%}$ & $\mathbf{1 5 \%}$ & $\mathbf{2 0 \%}$ \\
\hline Developing time (min) & 3.5 & 5.5 & 7 & 6.5 \\
Water absorption (\%) & 60.0 & 60.4 & 60.2 & 60.6 \\
Stability (min) & 20 & 25.5 & 32 & 28.5 \\
C max (Nm) & 1.106 & 1.126 & 1.054 & 1.098 \\
Weakening (Nm) & 0.04 & 0.00 & 0.00 & 0.00 \\
\hline
\end{tabular}

The results of wet gluten, gluten index and damage starch are presented in Table 7. The wet gluten was higher in case of $10 \%$ substitution by quinoa flour.

Damaged starch (DS) is important in bread making: it absorbs 4 times its weight in water as compared to 0.4 for native starch. Damaged starch granules are also subject to preferential attack by specific enzymes ( $\alpha$ and $\beta$-amylases). Some of these enzymes are incapable of attacking an intact granule because of the protective coating on the granules. The term "Damaged starch" is somewhat of a misnomer as the word "damaged" has a negative connotation implying something to be avoided. The higher damage starch content was obtained when $10 \%$ quinoa flour ratio was used. The level of starch damage directly affects the water absorption and the dough mixing properties of the flour and is of technological significance. Damaged starch absorbs 2 to 4 times more water than regular starch granules. Sticky doughs, high water absorption, longer proofing times, and red bread crust colour are just some of the effects of damaged starch. Damaged starch granules are susceptible to enzymatic degradation in comparison to native starches. 


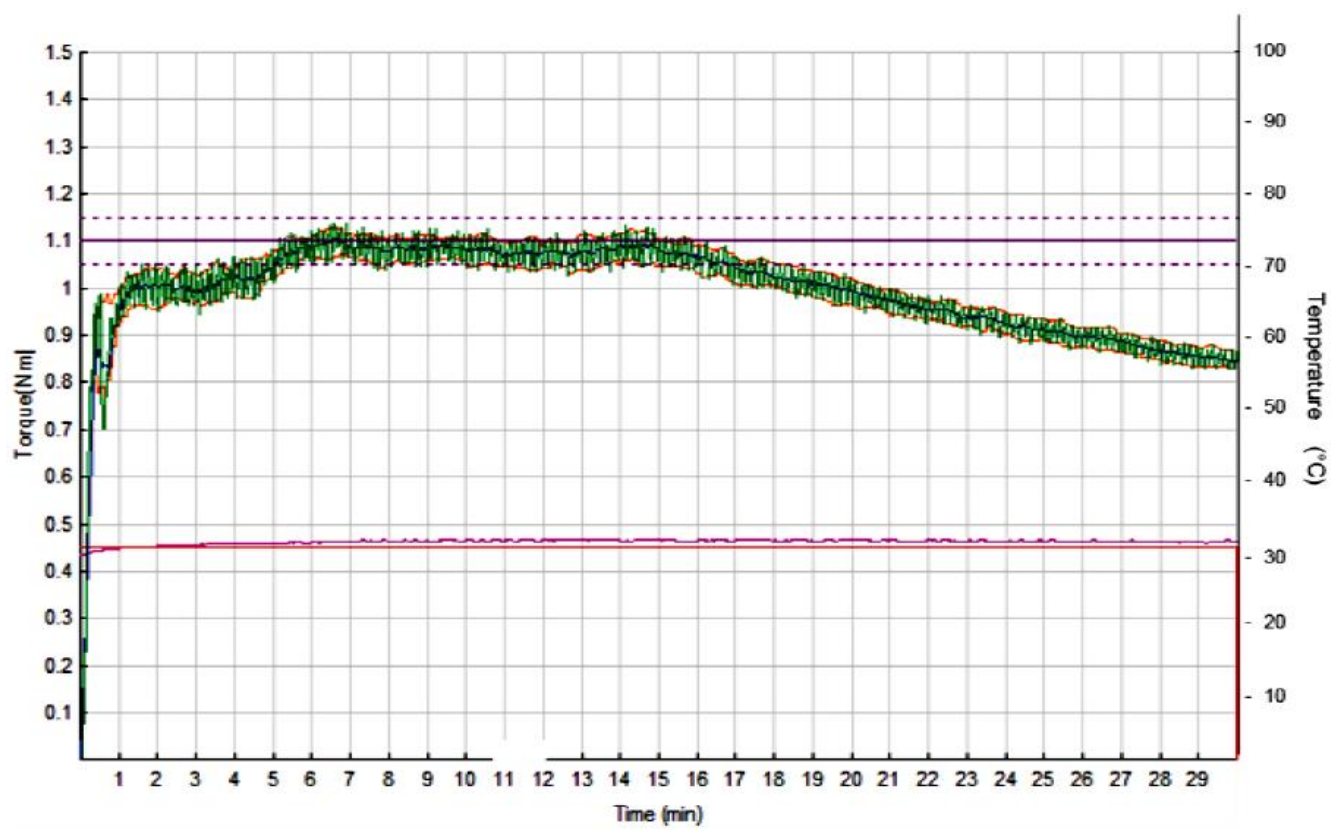

Fig. 1: Mixolab chart for the control sample (wheat flour)

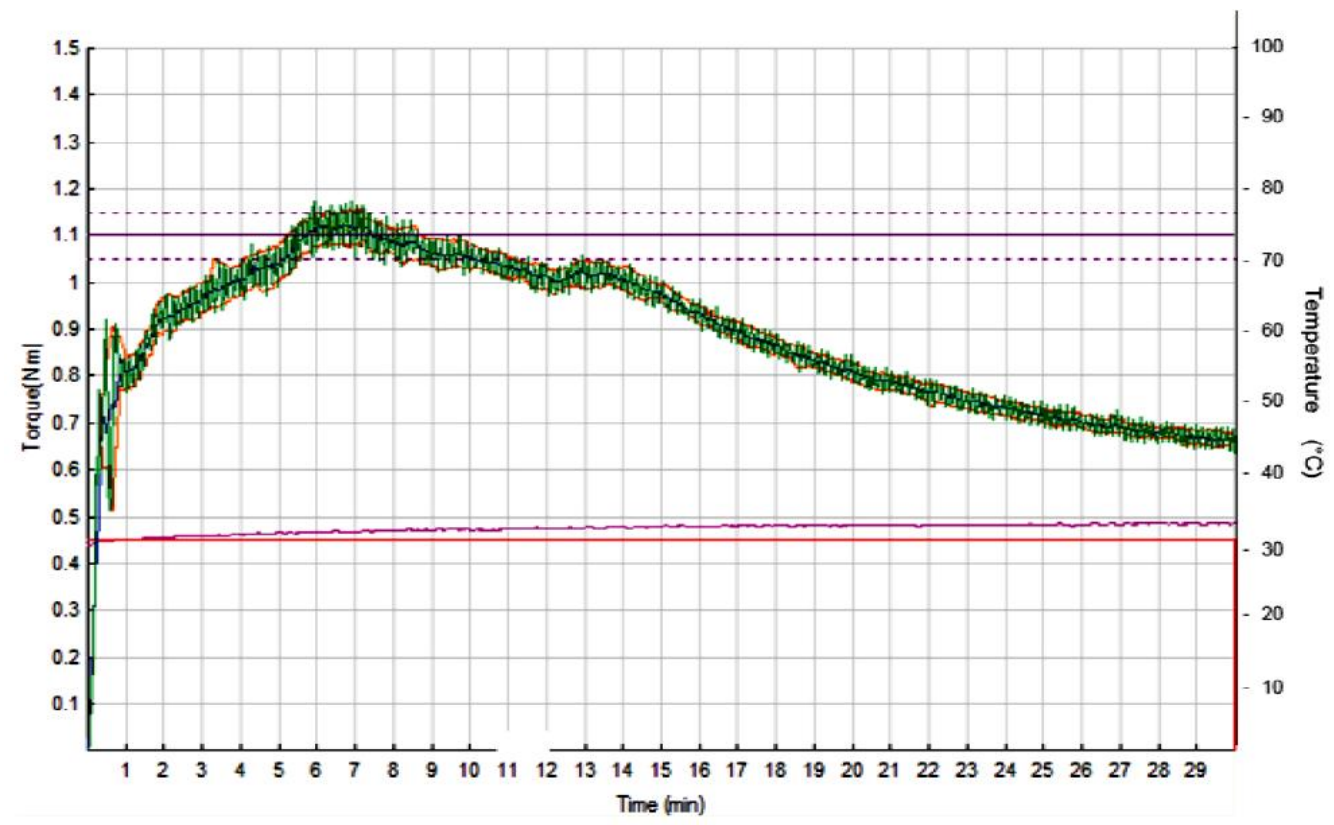

Fig. 2: Mixolab chart for $10 \%$ substitution with quinoa flour 


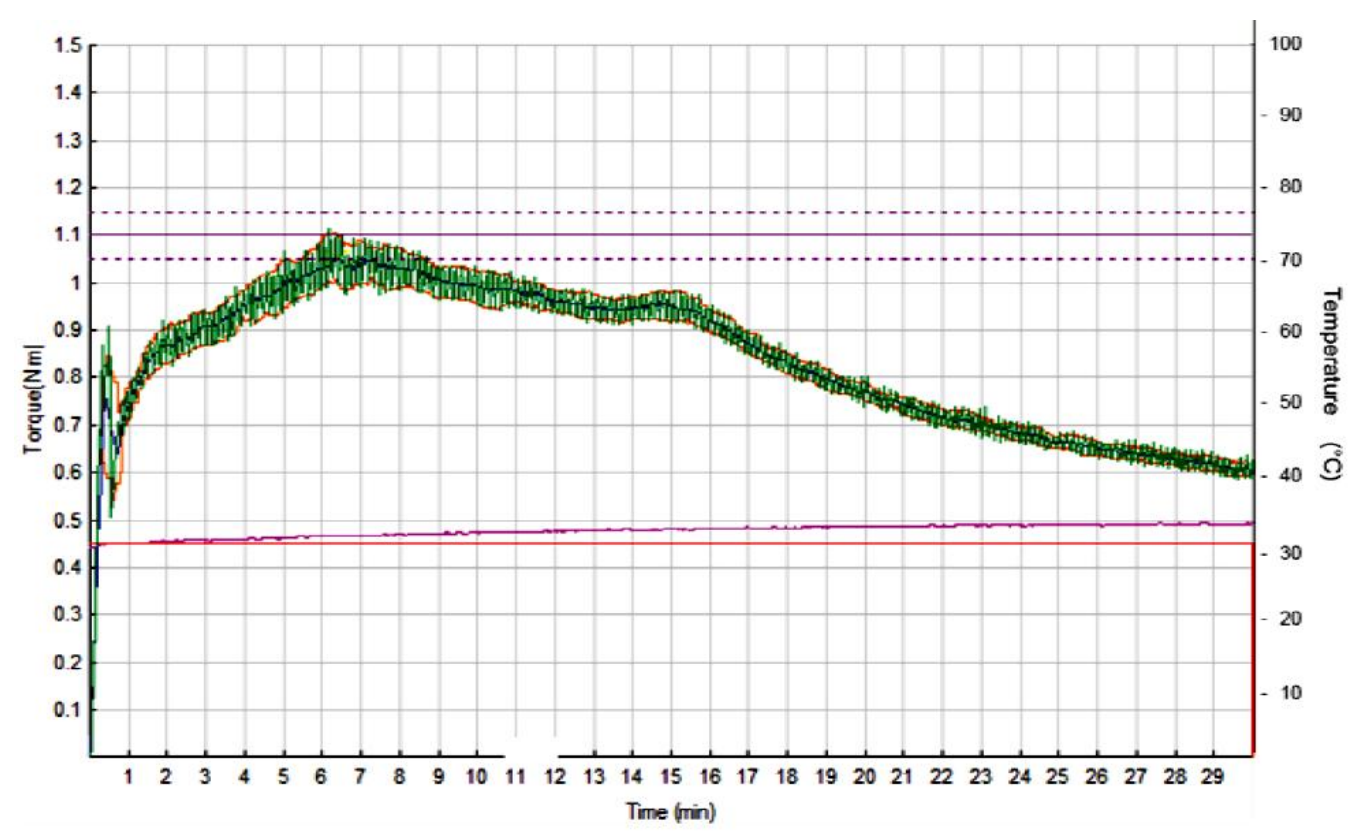

Fig. 3: Mixolab chart for $15 \%$ substitution with quinoa flour

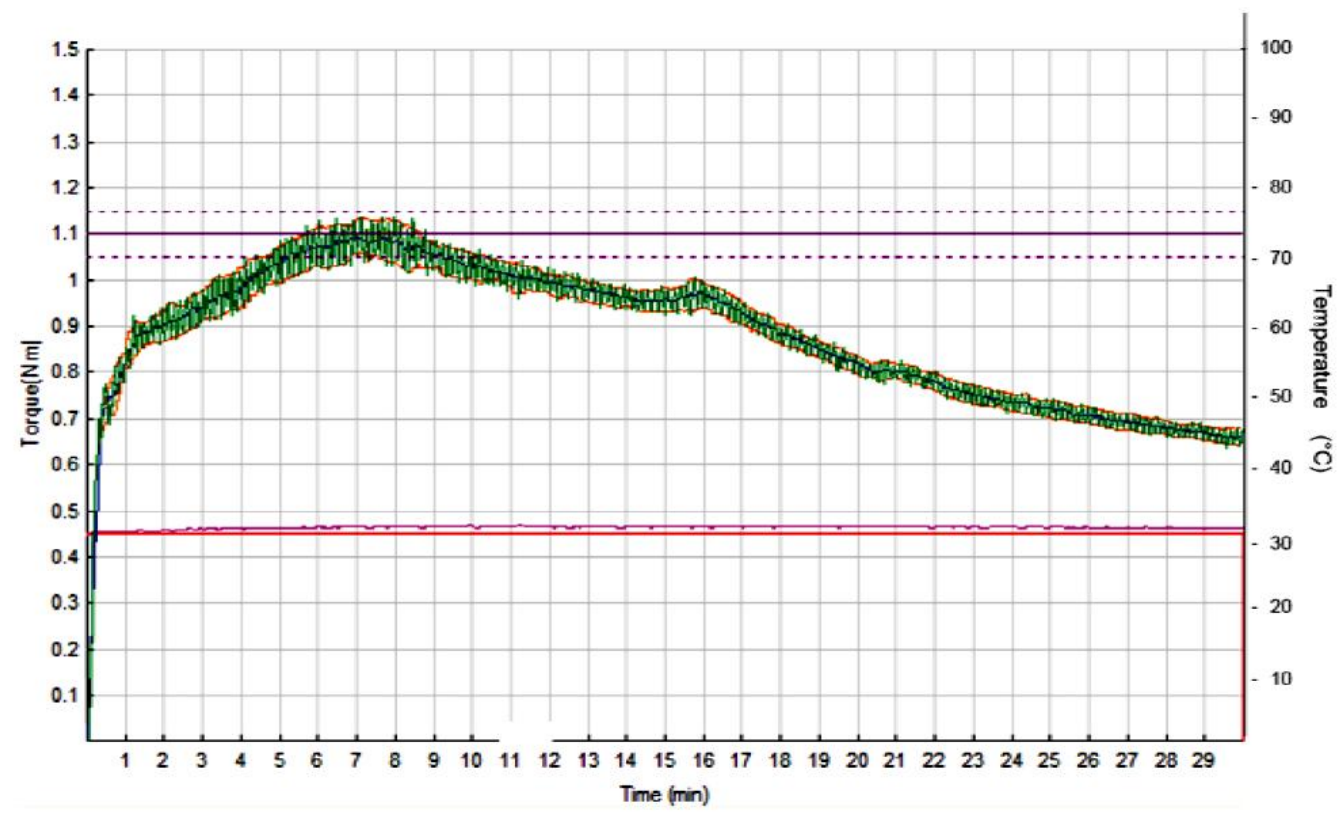

Fig. 4: Mixolab chart for $20 \%$ substitution with quinoa flour.

Table 7: Wet gluten, gluten index and damage starch $\%$ as affected by the addition of quinoa flour.

\section{Property}

Wet gluten \%

Gluten index

Damage starch

\section{Control}

$28.36 \pm 0.14$

$96.24 \pm 0.45$

$5.27 \pm 0.035$
The ratio of Quinoa flour added to wheat flour

\begin{tabular}{lll}
$\mathbf{1 0} \%$ & $\mathbf{1 5 \%}$ & $\mathbf{2 0 \%}$ \\
\hline $28.32 \pm 0.09$ & $28.22 \pm 0.17$ & $26.32 \pm 0.02$ \\
$88.76 \pm 0.37$ & $92.82 \pm 0.22$ & $92.32 \pm 0.38$ \\
$6.30 \pm 0.09$ & $5.82 \pm 0.02$ & $5.32 \pm 0.06$
\end{tabular}

There are several developments with quinoa flour at a smaller scale, like bread, cookies, muffins, pasta, snacks, drinks, flakes, breakfast cereals, baby foods, beer, diet supplements, and extrudates. 
The physical properties and sensory properties of pan bread prepared by mixing quinoa flour to wheat flour are shown in Table 8. The loaf specific volume decreased with the substitution with quinoa flour. The panellists found the crumb more dense and compact in bread $20 \%$ of quinoa flour compared to the control sample, Fig 5.
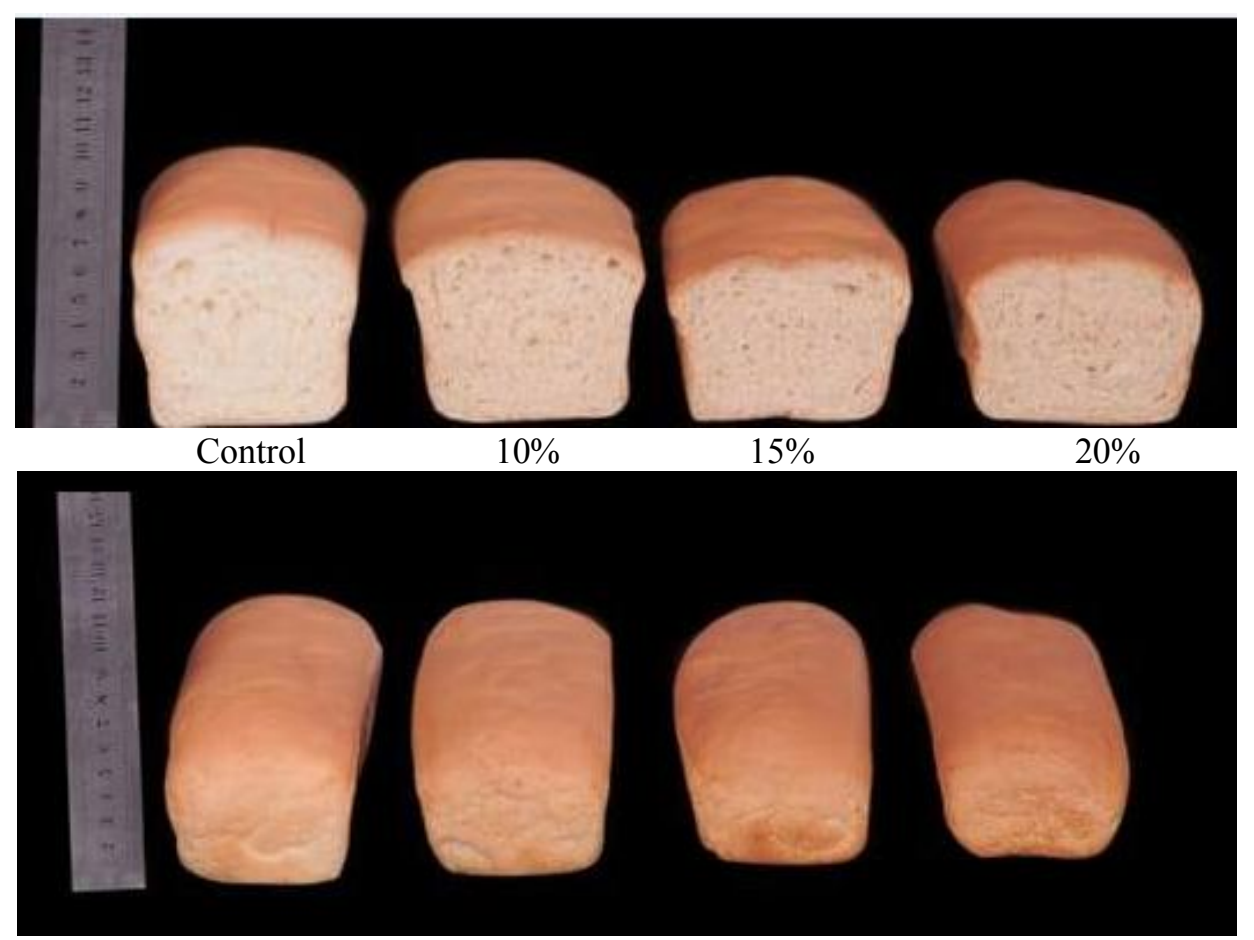

Fig 5: Pictures of bread loaves and slices.

The results for bread sensory analysis are shown in Table 8, significant differences among the experimental bread were found by the panellists, especially on the crust colour, crumb colour, and taste attributes. In detail, compared to wheat flour, the addition of quinoa flour caused a slight decrease in the perceived texture and taste. At the same time, the scores for the colour of the crust and the crumb, and overall taste attributes were acceptable.

Table 8: Some physical properties and sensory properties of pan bread prepared by mixing quinoa flour

\begin{tabular}{|c|c|c|c|c|}
\hline \multirow[t]{2}{*}{ Sample } & \multicolumn{4}{|c|}{ The ratio of Quinoa flour added to wheat flour } \\
\hline & $\begin{array}{c}\text { Control (0\%) } \\
\text { Wheat flour }\end{array}$ & $10 \%$ & $15 \%$ & $20 \%$ \\
\hline \multicolumn{5}{|l|}{ Physical properties } \\
\hline Volume $\left(\mathrm{cm}^{3}\right)$ & $1888.66 \pm 8.08$ & $1888.66 \pm 8.08$ & $1733.66 \pm 3.21$ & $1653.66 \pm 3.21$ \\
\hline Weight $(\mathrm{g})$ & $536.49 \pm 4.35$ & $534.80 \pm 4.88$ & $560.22 \pm 2.85$ & $580.20 \pm 1.14$ \\
\hline Specific volume $\left(\mathrm{g} / \mathrm{cm}^{3}\right)$ & 0.28 & 0.28 & 0.32 & 0.35 \\
\hline Highest $(\mathrm{cm})$ & $5.95 \pm 0.07$ & $5.95 \pm 0.07$ & $5.55 \pm 0.07$ & $5.60 \pm 0.14$ \\
\hline \multicolumn{5}{|l|}{ Sensory properties: } \\
\hline Taste & $9.00^{\mathrm{a}}$ & $8.14^{\mathrm{a}}$ & $7.42^{b}$ & $7.14^{\mathrm{b}}$ \\
\hline Crust colour & $9.28^{\mathrm{a}}$ & $8.71^{\mathrm{ab}}$ & 8.14 bc & $7.85^{\mathrm{c}}$ \\
\hline Crumb colour & $9.57^{\mathrm{a}}$ & $8.85^{\mathrm{a}}$ & $7.85^{\mathrm{b}}$ & $7.57^{\mathrm{b}}$ \\
\hline Odour & $9.14^{\mathrm{a}}$ & 8.85 a & $8.42 \mathrm{ab}$ & $7.71^{\mathrm{b}}$ \\
\hline Texture & $9.14^{\mathrm{a}}$ & $8.57 \mathrm{ab}$ & $7.85^{\mathrm{b}}$ & $7.71^{\mathrm{b}}$ \\
\hline Cell distribution & $9.42^{\mathrm{a}}$ & $9.14 \mathrm{ab}$ & 8.42 bc & $8.00^{\mathrm{c}}$ \\
\hline Apperance & $9.71^{\mathrm{a}}$ & $9.14^{\mathrm{a}}$ & $8.00^{\mathrm{b}}$ & $7.50^{\mathrm{b}}$ \\
\hline
\end{tabular}

In the case of pan bread, high specific volume is desired since it indicates proper aeration and porosity of the respective bread loaves (Gould, 2007). Gluten-free bread recipes typically feature bad 
gas-holding properties, leading to low volume (Houben et al., 2012). The substitution with $10 \%$ and $15 \%$ quinoa flour enhanced the specific volume compared to the control bread.

Bread parameters such as loaf specific volume, weight, crust and sensory properties were affected by the incorporation of quinoa, especially at $20 \%$ of addition, whereas the nutritional quality was increased. These new bread products were still accepted by the panellists.

Results in Table 9 show that increasing percentage of quinoa flour added to wheat flour causes to increase the content of both protein and fats in pan bread.

In conclusion, whole quinoa flour could be a good replacement for wheat flour in bread formulations, increasing the product's nutritional value in terms of dietary fiber, minerals, proteins and healthy fats, with only a small depreciation in bread quality at $15 \%$ of flour substitution.

Table 9: The proximate analysis of pan bread prepared by mixing quinoa flour to wheat flour

\begin{tabular}{lllll}
\hline Component (\%) & $\begin{array}{l}\text { Control (0\%) } \\
\text { Wheat flour }\end{array}$ & $\mathbf{1 0 \%}$ & $\mathbf{1 5 \%}$ & $\mathbf{2 0 \%}$ \\
\hline Protein & $11.07 \pm 0.14$ & $13.02 \pm 0.24$ & $15.03 \pm 0.56$ & $16.08 \pm 0.65$ \\
Fat & $3.41 \pm 0.43$ & $3.88 \pm 0.42$ & $3.78 \pm 0.72$ & $3.89 \pm 0.50$ \\
Ash & $1.56 \pm 0.78$ & $1.96 \pm 0.86$ & $2.04 \pm 0.71$ & $1.88 \pm 0.90$ \\
Moisture & $33.51 \pm 0.07$ & $33.62 \pm 0.10$ & $33.54 \pm 0.09$ & $34.03 \pm 0.18$ \\
Carbohydrates * & 50.45 & 47.34 & 45.61 & 44.12 \\
\hline
\end{tabular}

\section{Acknowledgement}

The authors are grateful to Eng. Mohamed Fathy abo-Dief for facilitating of studying the rheological properties of quinoa flour in the Arabian Company for Millers.

\section{References}

Alvarez-Jubete, L., H. Wijngaard, E. K. Arendt, and E. Gallagher, 2010. Polyphenol composition and in vitro antioxidant activity of amaranth, quinoa buckwheat and wheat as affected by sprouting and baking. Food Chemistry, 119, 770-778.

Brady, K., Ch. Hoa, R. Rosen, S. Sanga, and M. Karwe, 2007. Effects of processing on the nutraceutical profile of quinoa. Food Chem., 100(3): 1209-1216.

Chacaliaza-Rodríguez, L., G. Espinoza-Begazo, F. Ramos-Escudero, K. Servan, 2016. Proximate Chemical Composition and Content of Biologically Active Components in Leaves of Two Quinoa Cultivars (Salcedo and Altiplano) Produced in Peru. Research Journal of Medicinal Plants. 10 (8): 450-456.

Chauhan, G., N. Eskin, and P. Mills, 1999. Effect of saponin extraction on the nutritional quality of quinoa (Chenopodium quinoa Willd.) proteins. J. Food Sci. Technol., 2, 123-126.

Cubadda, R., M. Carcea, L.A. Pasqui, 1992. Suitability of the gluten index method for assessing gluten strength in durum wheat and semolina. Cereal Foods World, 37 (12): 866-869.

Debet, M. R., and M. J. Gidley, 2007. Why do gelatinized starch granules not dissolve. Food Agric., $80,152-156$.

El-Porai, E.S., A.E. Salama, A.M. Sharaf, A.I. Hegazy, M.G.E. Gadallah, 2013. Effect of different milling processes on Egyptian wheatflour properties and pan bread quality. Annals of Agricultural Science, 58(1)51-59.

Francis, G., Z. Kerem, H. Makkar, and K. Becker, 2002. The biological action of saponins in animal systems: A review. British J. Nutr. 88, 587-605.

Gee JM, Price KR, Ridout CL, Wortley GM, Hurrel RF and Johnson IT, Saponins of quinoa (Chenopodium quinoa): effect of processing ontheir abundance in quinoa products and their biological effects on intestinal mucosal tissue.J Sci Food Agric 63:201 - 209 (1993)

Gould J.T. 2007. Baking around the world. In: Technology of Breadmaking. Eds. S.P. Cauvain, L.S. Young. New York: Springer, pp. 223-243.

Harborne, J.B. 1973. Phytochemical methods, 1st Ed. London: Chapman and Hall, Ltd. p. 49-188. 
Hirose, Y., T. Fujita, T. Ishii, N. Ueno, 2010. Antioxidative properties and flavonoid composition of Chenopodium quinoa seeds cultivated in Japan. Food Chem., 119:1300-1306.

Hossam, K. and N. Helmy, 2014. The economics of quinoa production to address the food problem security and reduce food poverty gap in Egypt. Middle East Journal of Applied Sciences, 4(1): $122-141$.

Houben, A., A. Höchststötter, and T. Becker, 2012. Possibilities to increase the quality in gluten-free bread production: an overview. Euro. Food Res. Technol., 235,195- 208.

Jacobsen, S.E., 2003. The worldwide potential of quinoa (Chenopodium quinoa Willd.). Food Reviews International 19, $167 \mathrm{e} 177$.

Jayanthi, P. and P. Lalitha, 2011. Reducing power of the solvent extracts of Eichhornia crassipes (MART) Solms. International Journal of Pharmacy and Pharmaceutical Sciences.3:126-128.

John, B., C.T. Sultiman, S. George, and R. Reddy, 2014. Spectrophotometric estimation of total alkaloids in selected Justicia species. International Journal of Pharmacy and Pharmaceutical Sciences. 6(5):647-648.

Konishi, Y., S. Hirano, H. Tsuboi, and M. Wada, 2004. Distribution of minerals in quinoa (Chenopodium quinoa Willd.) seeds. Biosci Biotechnol Biochem., 68:231-234.

Koziol, M.J. 1992. Chemical composition and nutritional evaluation of quinoa. J. Food Comp. Anal. 5:35-68.

Kovacs, M.I.P., B.X. Fu, S.M. Woods, K. Khan, 2004.Thermal stability of wheat gluten protein: its effect on dough properties and noodle texture. J. Cereal Sci., 39: 9-19.

Mart'inez EA, Veas E, Jorquera C, San Mart'in R and Jara P, Reintroduction of Chenopodium quinoa Willd. into arid Chile: cultivation of two lowland races under extremely low irrigation. J Agron Crop Sci., 195:1-10 (2009).

Mastebroek, H.D., H. Limburg, T. Gilles, and H.J.P. Marvin, 2000. Occurrence of sapogenins in leaves and seeds of quinoa (Chenopodium quinoa Willd.). Journal of the Science of Food and Agriculture 80(1): 152-156.

Mis, A., 2000. Some methodological aspects of determining wet gluten quality by the Glutomatic Method (a laboratory note), International Agrophysics, 14, 263-267. New York, pp. $223 \mathrm{e} 244$.

Nowak, V., J. Du, and C. Ute, 2015. Assessment of the Nutritional Composition of Quinoa (Chenopodium quinoa Willd.). Food Chemistry. 193.47-54

Nsimba, R.Y., H. Kikuzaki, and Y. Konishi, 2008. Antioxidant activity of various extracts fractions of Chenopodium quinoa and Amaranthus spp. seeds. Food Chem., 106:760-766.

Ozgen. M., C. Durgac, S. Scrce and C. Kaya, 2008. Chemical and antioxidant properties of pomegranate cultivars grown in the Mediterranean region of Turkey. Food Chemistry, 111:703-706.

Ruales, J. and B.M. Nair. 1992. Nutritional quality of the protein in quinoa (Chenopodium quinoa Willd) seeds. Plant Foods Hum. Nutr. 42(1):1-12.

Ruales, J. and B.M. Nair, 1993. Content of fat, vitamins and minerals in quinoa (Chenopodium quinoa Willd.) seeds. Food Chem., 48, 131-136.

Piggott, I.R. (1988). Sensory Analysis of Foods. $2^{\text {nd }}$ edition. Elsevier Applied Science, London, New York.

Schlick, G. and D.L. Bubenheim. 1993. Quinoa: An emerging "new" crop with potential for CELSS. NASA Tech. Paper \#3422.

Silva, E.M., H. Rogez, and Y. Larondelle, 2007. Optimization of extraction of phenolics from Inga edulis leaves using response surface methodology. Sep Purif Technol., 55:381-387.

Singleton,V. L., A. Joseph, and J.R. Rossi, 1965. Colourimetry of total phenolics with phosphomolybdic-phosphotungstic acid reagents. American Journal of Enology and Viticulture.16: 144-153.

Skrovankova, S., D. Sumczynski, J. Mlcek, T. Jurikova, and J. Sochor, 2015. Bioactive compounds and antioxidant activity in different types of berries. Int. J. Mol. Sci., 16(10):24673-24706. http://dx.doi.org/10.3390/ijms161024673.

Soliz-Guerrero JB, Jasso de Rodr' iguez D, Rodr' 1guez-Garc'ia R, Angulo-Śanchez JL and ḾendezPadilla G,Quinoa saponins: concentrationand composition analysis, inTrends in New Crops and New Uses,ed.by Janick J and Whipkey A. ASHS Press, Alexandria, VA, pp. 110 - 114(2002).

Sparg, S., M. Light, and J. van Staden, 2004. Biological activities and distribution of plant saponins. J. Ethnopharmacol. 94(2-3): 219-243. 
Steel, R.G.D., and J.H. Torrie, 1980. Principals and Procedures of Statistics. London. McGraw Hill. The technology of Bread making, second ed. Springer Science and Business Media,

Stuardo M and San Mart in R, Antifungal properties of quinoa (Chenopodium quinoa Willd.) alkali treated saponins against Botrytis cinerea Ind Crops Prod $27: 296$ - 302 (2008).

Tarade KM,Singhal RS,Jayram RV and Pandit AB, Kinetics of degradation of saponins in soybean flour (Glycine max) during food processing.J Food Eng 76:440 - 445 (2006).

Zhu, N., S. Sheng, S. Sang, S. Jhoo, S. Bai, M. Karwe, R. Rosen, and C. Ho, 2002. Triterpene saponins from debittered quinoa (Chenopodium quinoa) seeds. J. Agric. Food Chem. 50, 865-867. 